\title{
Experimental study of nucleate pool boiling of FC-72 on micro-pin-finned surface under microgravity
}

\author{
Yan-Fang Xue ${ }^{\text {a }}$, Jian-Fu Zhao ${ }^{b}$, Jin-Jia Wei ${ }^{\text {a,* }}$, Yong-Hai Zhang ${ }^{\text {a }}$, Bao-Jin Qi ${ }^{\text {a }}$ \\ a State Key Laboratory of Multiphase Flow in Power Engineering, Xi'an Jiaotong University, Xi'an 710049, China \\ ${ }^{\mathrm{b}}$ Key Laboratory of Microgravity (National Microgravity Laboratory)/CAS, Institute of Mechanics, Chinese Academy of Sciences, Beijing 100190, China
}

\section{A R T I C L E I N F O}

\section{Article history:}

Received 10 July 2012

Received in revised form 28 March 2013

Accepted 31 March 2013

Available online 3 May 2013

\section{Keywords:}

Microgravity

Pool boiling

Heat transfer enhancement

Micro-pin-fin

\begin{abstract}
A B S T R A C T
In order to effectively enhance the boiling heat transfer under microgravity, experiments were performed using micro-pin-finned structure as heater surface in subcooled nucleate pool boiling of FC-72 under short-term microgravity condition utilizing the drop tower Beijing. Micro-pin-fins with the dimensions of $30 \times 60 \mu \mathrm{m}^{2}$ (thickness $\times$ height) and the space of $30 \mu \mathrm{m}$ were fabricated on the surface of square silicon with the dimensions of $10 \times 10 \times 0.5 \mathrm{~mm}^{3}$ by using the dry etching technique. The results were compared with previous published data of smooth chip both in normal gravity and microgravity conditions. The micro-pin-finned chip showed a considerable heat transfer enhancement in the nucleate boiling region with higher upper limit heat flux and lower mean heater surface superheat compared to chip $S$ under microgravity condition. The high-efficient heat transfer performance of FC-72 on the micro-pinfinned surface is independent of gravity, which stems from the sufficient supply of fresh liquid to heater surface due to the capillary forces.
\end{abstract}

Crown Copyright (c) 2013 Published by Elsevier Ltd. All rights reserved.

\section{Introduction}

With the rapid development of MEMS processing technology, the size of the electronic equipments is significantly reduced and the processing speed and memory capacity are substantially increased, resulting in a rapid increasing of power dissipation rate at the chip, module and system levels. Sophisticated electronic cooling technology is needed to maintain a relatively constant component temperature below the upper limit for the reliable operation of chips. Direct liquid cooling with phase change using dielectric liquids such as FC-72 is a prospective scheme for highpowered electronic devices due to the latent heat transport during liquid evaporation. This technique has been widely applied to electronic component cooling on earth and has been studied for a long time for the purpose of heat transfer enhancement. Meanwhile, electronic cooling by using boiling heat transfer in space and in planetary neighbors has become an increasing significant subject due to its high efficiency in heat transfer. However, for the boiling heat transfer in microgravity, the buoyancy effect becomes weak, resulting in a longer stay time for the bubble departure. Thus, film boiling and burnout can occur in microgravity at heat fluxes much lower than those required on earth. A stable heat transfer process in space will be required to remove heat effectively, efficiently, and safely with increasing space activities. How to improve boiling heat

\footnotetext{
* Corresponding author. Tel.: +86 02982664462.

E-mail address: jjwei@mail.xjtu.edu.cn (J.-J. Wei).
}

transfer effectively in microgravity is an important issue. Moreover, from the space thermal engineering viewpoint [1], the next step in microgravity pool boiling studies is to find out an appropriate means to effectively enhance the boiling heat transfer under microgravity.

Previous research has shown that fabrication of microstructures on the chip surfaces can effectively enhance boiling heat transfer. These include a dendritic heat sink [2], laser-drilled holes [3], micro-re-entrant cavities (1-3 $\mu \mathrm{m}$ in mouth dia.) [4], porous surfaces formed by spraying and painting of alumina particle [5] or copper particle (3-10 $\mu \mathrm{m}$ in dia.) [6,7]. All the above treated surfaces show the drawback of severe deterioration in boiling heat transfer in the high heat flux region, and the wall temperature at the critical heat flux (CHF) is higher than the upper limit, $85^{\circ} \mathrm{C}$, for the reliable operation of LSI chips. The deterioration of these surfaces performance is caused by a large number of mushroom bubbles staying above the surface microstructure, which prevented the bulk liquid from contacting the superheated wall for vaporization. Since 2002, Honda and Wei [8-12] have made a series of experimental study on boiling heat transfer enhancement by use of micro-pin-fins (10-50 $\mu \mathrm{m}$ in thickness and $60-200 \mu \mathrm{m}$ in height) which were fabricated by dry etching. From the boiling incipience to the critical heat flux, the micro-pin-finned surfaces showed a sharp increase in the heat flux with increasing wall superheat. The increase of CHF could reach more than three times that of a smooth chip, and the wall temperature at the $\mathrm{CHF}$ point was lower than $85^{\circ} \mathrm{C}$. In the high heat flux region, although the micro-pin-finned 


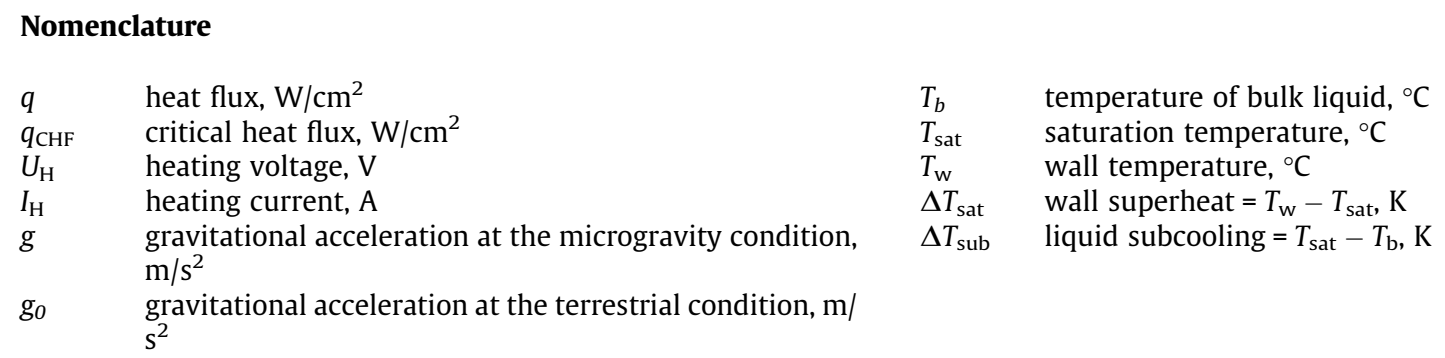

surfaces are covered with large bubbles as smooth or previous microstructures surfaces, the capillary force generated by the bubbles resting on the micro-pin-fins drives plenty of fresh liquid into contact with the superheated wall for vaporization through the regular interconnected structures formed by micro-pin-fins, as well as improves the micro-convection heat transfer by the motion of liquid around the micro-pin-fins. These produce high heat transfer efficiency until the capillary force reaches its maximum value. The capillary force increases with decreasing fin pitch with a penalty that causes the hydraulic resistances of the wet liquid supply to increase.

Therefore, there exists an optimum fin pitch for a compromise. According to our previous studies [8-12], the fin size of 30-50 $\mu \mathrm{m}$ appears to be a preferable size for the design of micro-pin-finned surfaces in the enhancement of nucleate boiling heat transfer. Following the enhanced boiling heat transfer mechanisms for the micro-pin-finned surfaces, it is supposed that although the bubbles staying on the top of the micro-pin-fins cannot detach soon in microgravity, the fresh bulk liquid may still access to the heater surface through interconnect tunnels formed by the micro-pin-fins due to the capillary forces, which is independent of the gravity level. Therefore, it is our great interest to study the boiling heat transfer performance of micro-pin-finned surfaces in microgravity.

The current status of experimentation in variable gravity has been recently reviewed by Di Marco [13]. On the progress in this field, several comprehensive reviews are available. For example,
Straub [14] issued a comprehensive review of his own activity in microgravity boiling research from the early 1980s to date. Subsequently, Di Marco [15], Kim [16], Ohta [17], and Zhao [18] issued reviews of microgravity boiling researches in Europe, US, Japan, and China, respectively. To date no research has been found in the open literature on the effects of enhanced surfaces on nucleate pool boiling heat transfer in microgravity. This study examines and elucidates about the effects of micro-pin-finned surfaces on nucleate pool boiling heat transfer of FC-72 under terrestrial and microgravity conditions. The enhanced boiling heat transfer mechanisms for the micro-pin-finned chip under microgravity condition were discussed. The experiments of subcooled pool boiling of FC-72 from silicon chips fabricated with micro-pin-fins were carried out utilizing the drop tower Beijing, which can provide a gravity level of $10^{-3} g_{0}$ (here $g_{0}=9.81 \mathrm{~m} / \mathrm{s}^{2}$ ) with duration of about $3.6 \mathrm{~s}$. A smooth chip was also presented from Xue et al. [19] for comparison.

\section{Experimental apparatus and procedure}

\subsection{Experimental apparatus}

A simple but useful pool boiling test facility system designed for the present drop tower experiments is shown schematically in Fig. 1. The boiling vessel was made of polycarbonate which allowed for visualizing boiling phenomena and had a size of

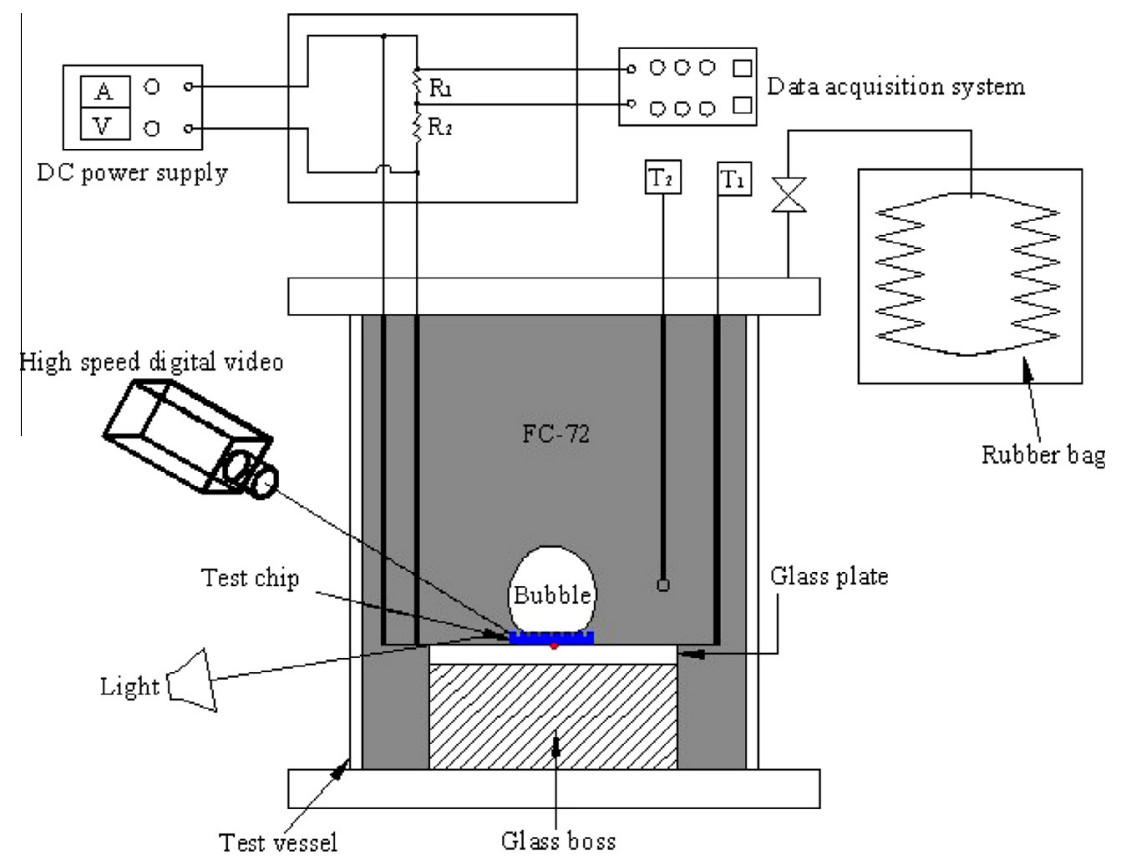

Fig. 1. Schematic diagram of the experimental apparatus. 
$100 \times 100 \times 100 \mathrm{~mm}^{3}$. About $1 \mathrm{~L}$ of FC-72 with dissolved gas was filled in the vessel as a test liquid. In order to maintain the pressure in the test vessel at atmospheric pressure, a rubber bag was attached to the test vessel. A test section consisting of a silicon chip bonded on a plexiglass plate and fixed on a base made of polycarbonate was horizontally bonded on the bottom of the test vessel, with the silicon chip facing upward. A $0.13-\mathrm{mm}$ diameter T-type thermocouple for the local wall temperature $\left(T_{1}\right)$ measurement was bonded on the bottom surface of test chip at the center using adhesive of insulation and heat conduction (5295F, $k=1.1 \mathrm{~W} / \mathrm{m} \mathrm{K}$ ). Then, the test chip was bonded on the top of plexiglass plate using an epoxy adhesive of insulation and thermal isolation (MOMENTIVE RTV108, $k=0.12 \mathrm{~W} / \mathrm{m} \mathrm{K}$ ). Also, the silicon chip has a high thermal conductivity $(k=120 \mathrm{~W} / \mathrm{m} \mathrm{K})$ and the thickness of test chip was $0.5 \mathrm{~mm}$, thus, the temperature of heating surface can be obtained from the measured temperature at the center of test chip bottom surface with a small correction (less than $1 \mathrm{~K}$ ) for wall conduction. The local temperature of the test liquid $\left(T_{2}\right)$ was measured by a $0.3-\mathrm{mm}$ diameter T-type thermocouple which was located at about $20 \mathrm{~mm}$ apart from the edge of the test chip and $40 \mathrm{~mm}$ above the chip level in order to avoid the effect of bubble dynamics. The change of measured temperature of bulk liquid is less than $0.5 \mathrm{~K}$ during every test run about $90 \mathrm{~min}$ in the whole experimental process. The two thermocouples for the measurements of liquid and wall temperatures were first connected with a temperature transmitter and then connected to data acquisition system (DI710-UHS). The uncertainties in the chip and bulk liquid temperature measurements by the thermocouples were estimated to be less than $0.3 \mathrm{~K}$. Wall temperature uncertainty can be attributed to the errors caused by thermocouple calibration by a platinum resistance thermometer $(0.03 \mathrm{~K})$, temperature correction for obtaining surface temperature from the measured value at the bottom of the chip $(0.2 \mathrm{~K})$, the temperature unsteadiness $(0.1 \mathrm{~K})$ and the thermocouple resolution (less than $0.1 \mathrm{~K}$ ). The uncertainty of the bulk temperature is due to errors caused by thermocouple calibration by a platinum resistance thermometer $(0.03 \mathrm{~K})$, the temperature unsteadiness $(0.2 \mathrm{~K})$ and the thermocouple resolution (less than $0.1 \mathrm{~K}$ ).

Details of the test section are shown in Fig. 2. The test chip was a $\mathrm{P}$ doped $\mathrm{N}$-type silicon chip with the dimensions of $10 \times 10 \times 0.5 \mathrm{~mm}^{3}$. Micro-pin-fins were fabricated by the dry etching technique on the chip surface for enhancing boiling heat transfer. The fin thickness is $30 \mu \mathrm{m}$ and fin height is $60 \mu \mathrm{m}$. The fin spacing (distance between fins) is the same as the fin thickness. A smooth chip was also presented for comparison. These two kinds of silicon chips were named chips S and PF30-60, respectively. The scanning electron microscope (SEM) image of chip PF30-60 is shown in Fig. 3; the lower column in the figure shows a close-up of micro-pin-fins. Detailed description about the properties of the test chips were reported in our previous paper [10]. The chip was Joule heated by a direct current or voltage. Two $0.25-\mathrm{mm}$ diameter copper wires were soldered with a lower temperature solder (the melting point of $180^{\circ} \mathrm{C}$ ) to the side surfaces at the opposite ends of test chip that supply power to the chip by a direct current or voltage. In order to secure the ohmic contact between the semiconductor silicon chip and the copper wire, a special solder with the

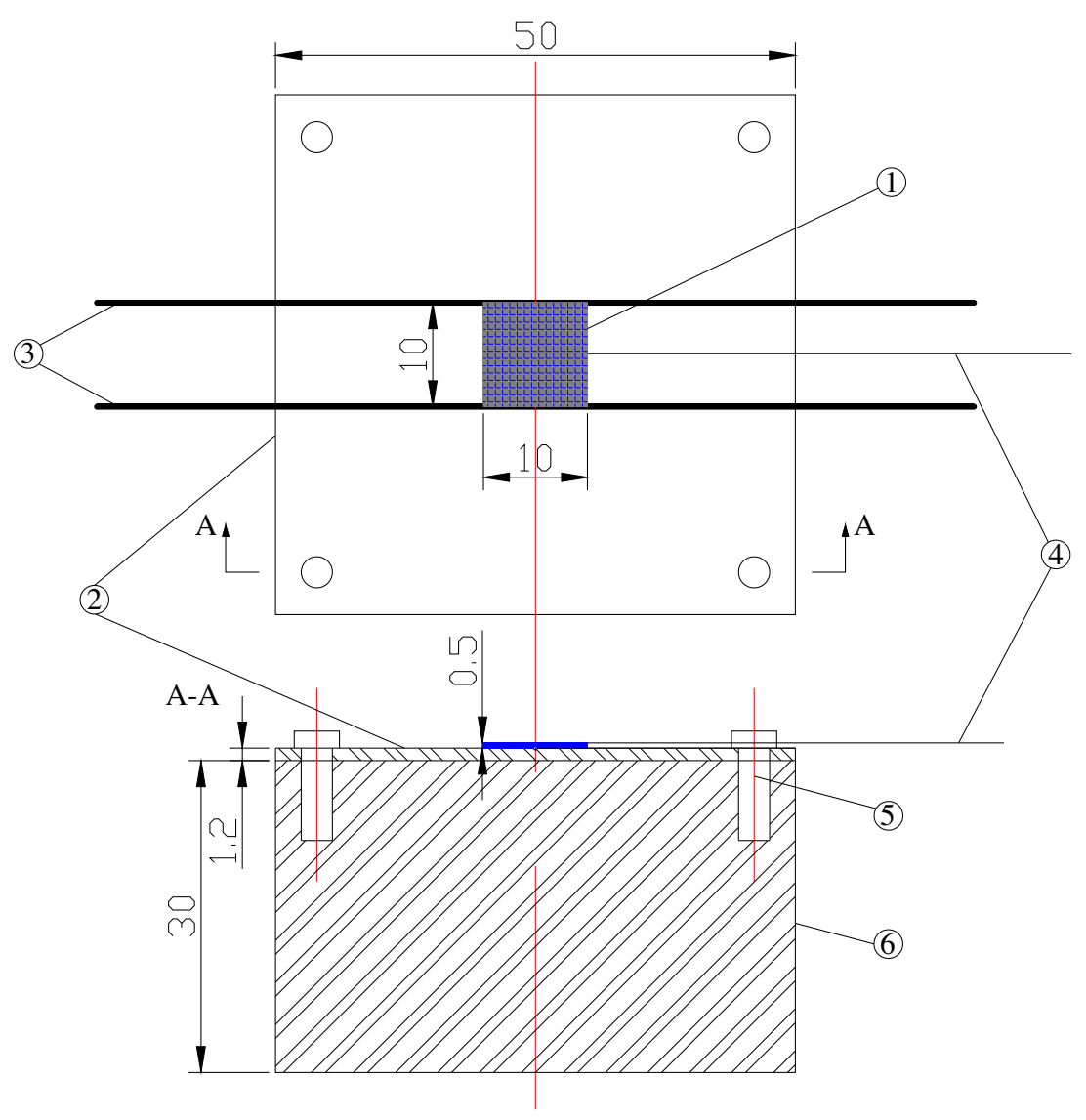

1.Silicon chip 2.Plexiglass plate 3.Copper lead wire 4.Thermocouple

5.Bolts 6.Plexiglass base

Fig. 2. Details of test section. 


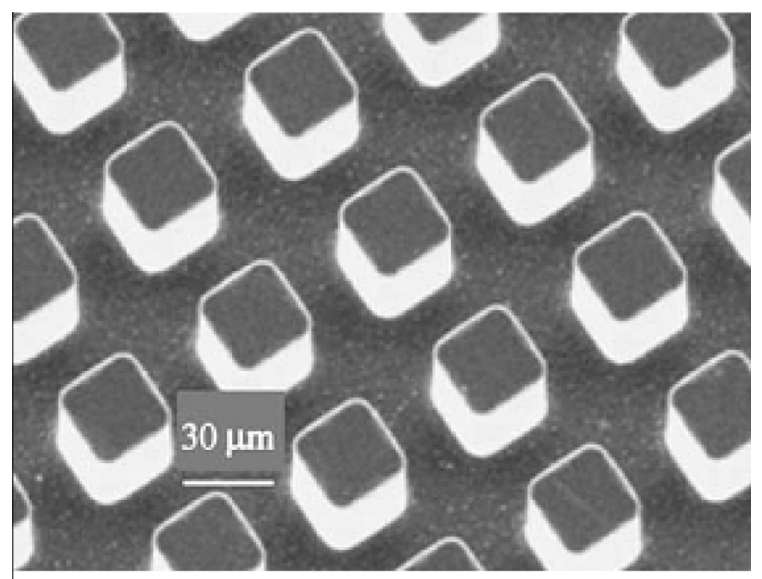

Chip PF30-60

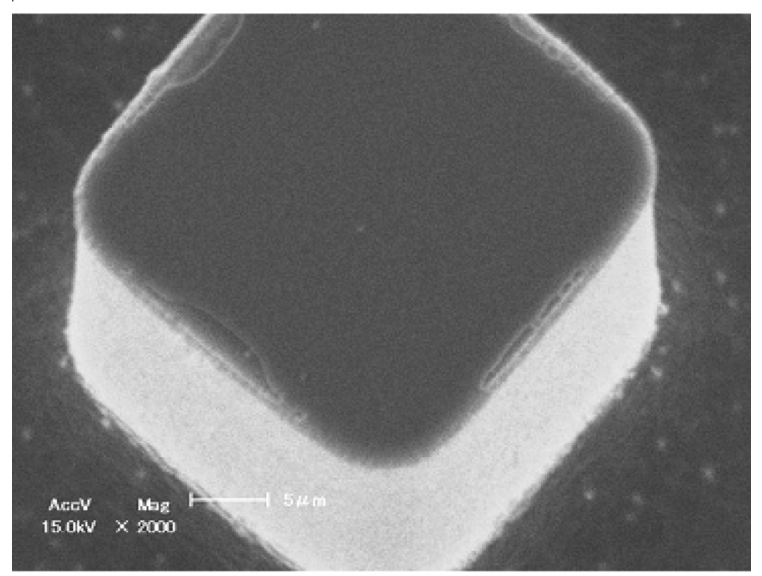

Close-up view

Fig. 3. SEM image of micro-pin-fins.

melting point of $300{ }^{\circ} \mathrm{C}$ was applied to the silicon chip with ultrasonic bonding method before soldering the copper wires. The contact resistance between the silicon chip and the copper wires can be greatly reduced to be negligible by this method. The test chip was bonded on a $50 \times 50 \times 1.2 \mathrm{~mm}^{3}$ plexiglass plate using epoxy adhesive and then fixed on the plexiglass base which was bonded on the bottom of the test vessel. This facilitated an easy exchange of the silicon chip and minimization of conduction heat loss. The side surfaces of the chip were covered with an adhesive to minimize heat loss. Therefore, only the upper surface of the chip was effective for heat transfer. A programmable DC power supply was connected in parallel to two series resistances $\left(R_{1}=5 \mathrm{k} \Omega\right.$, $R_{2}=100 \mathrm{k} \Omega$ ) and the silicon chip. The two series resistances were used to measure the voltages across the silicon chip in the circuit. The electric current through the silicon chip was measured by a Hall transducer and then connected to the data acquisition system (DI710-UHS). Thus, the heat flux input, $q$, (defined on the projected area basis) was obtained from the voltage drop of the test chip and the electric current through the chip. Heat flux uncertainty is consisted of the errors of electric power per unit area supplied to the chip, heat loss ratio through substrate conduction and transient effect ratio due to the change of internal energy of chip, respectively. Measurement errors of voltage $U$, current $I$ and side length $l$ are $0.1 \%, 0.014 \%$ and $0.5 \%$, respectively. The heat loss ratio through substrate is about $5.0 \%$ and the transient effect ratio is about $0.3 \%$. So the uncertainty in heat flux is estimated as approximately $6 \%$ for steady boiling heat transfer and $6.3 \%$ for quasi-steady boiling heat transfer.

\subsection{Test procedure and conditions}

Because of the stringent constraints in terms of space and weight of experimental apparatuses in the drop tower capsule, we used a simple and compact test system for research. For the visual observation of liquid-vapor behavior, a CCD video camera was installed in front of the test vessel at a direction angle of $45^{\circ}$ with respect to the heater surface, and the phenomena were recorded at a speed of 25 frames per second. Simultaneously, a high speed digital camera (VITcam CTC) imaging 500 frames per second at a resolution of $1024 \times 640$ pixels with a shutter speed of $1 / 2000 \mathrm{~s}$ was used along with a lens (Computar MLM-3XMP) to obtain images of the boiling process. The high speed digital camera was installed in front of the test vessel at a direction angle of $30^{\circ}$ with respect to the heater surface.

Experiments were conducted both in terrestrial gravity before the drop capsule release and in short-term microgravity during free falling of the drop capsule in the drop tower Beijing. The facility satisfied the safety criteria to expose the apparatus in the drop capsule to different gravitational environments varying between microgravity $\left(\mu g ; 10^{-3} g_{0}\right)$ in the free falling period and high- $g$ level in the deceleration recovery system $\left(16 g_{0}\right)$.

Outline of experimental procedure during a free falling of drop capsule is described as follows. The test chip was heated by setting a constant input current or voltage for the desired heat flux to initiate boiling on the heater surface. After the heat transfer reached a steady state in about $4 \mathrm{~min}$ before the drop capsule release, the free falling of drop capsule started which could provide approximately $3.6 \mathrm{~s}$ effective microgravity environment. The high-speed digital video camera could work for a duration time of $8 \mathrm{~s}$, which was divided into two sections by an external trigger signal. The bubble behaviors in normal gravity before the release of the drop capsule was recorded in the first section $(15 \% \times 8)$ for a duration time of about $1.2 \mathrm{~s}$, while those in microgravity after the release was recorded in the other section $(85 \% \times 8)$ for a duration time of about $6.8 \mathrm{~s}$. Moreover, the data measurement and the video

Table 1

Experimental conditions for chip PF30-60.

\begin{tabular}{|c|c|c|c|c|c|c|}
\hline $\operatorname{Run}^{\#}$ & Pressure $p(\mathrm{kPa})$ & Liquid temperature $T_{1}\left({ }^{\circ} \mathrm{C}\right)$ & Subcooling $\Delta T_{\text {sub }}(\mathrm{K})$ & Heating voltage $U_{\mathrm{H}}(\mathrm{V})$ & Heat flux $q\left(\mathrm{~W} / \mathrm{cm}^{2}\right)$ & Heating current $I_{\mathrm{H}}(\mathrm{A})$ \\
\hline I26 & 103.4 & 11.5 & 44.5 & 27.7 & 7.2 & $(0.26)^{\mathrm{a}}$ \\
\hline I34 & 102.9 & 13.7 & 42.2 & 36.9 & 12.53 & $(0.34)$ \\
\hline $\mathrm{I} 42$ & 103.4 & 11.7 & 44.3 & 46.3 & 19.44 & $(0.42)$ \\
\hline I50 & 103.3 & 11.8 & 44.2 & 54.4 & 27.2 & $(0.50)$ \\
\hline U55 & 101.7 & 25.1 & 30.4 & (55) & 27.89 & 0.51 \\
\hline U60 & 100.7 & 22.9 & 32.4 & (60) & 33 & 0.55 \\
\hline U63 & 100.7 & 24.0 & 31.3 & (63) & 36.07 & 0.57 \\
\hline U66 & 100.9 & 23.2 & 32.1 & $(66)$ & 39.54 & 0.60 \\
\hline
\end{tabular}

a Values in bracket denote the pre-adjusted parameter. 
recording were operated simultaneously. Due to the reason of drop tower Beijing technical reform, the experiments were divided into two stages. The first stage before technical reform was adopted in constant heating current method for heating silicon chip. The liquid subcooling keeps at about $43 \mathrm{~K}$ (corresponding to $12.3^{\circ} \mathrm{C}$ of bulk liquid temperature) which is caused by ambient temperature. After that, in order to attain high heat flux in microgravity, thus, the heating method with constant heating voltage was used to avoid damage to the chip. Also, the liquid subcooling keeps at about $32 \mathrm{~K}$ (corresponding to $23.8^{\circ} \mathrm{C}$ of bulk liquid temperature) which is also caused by ambient temperature. The detail experimental conditions are summarized in Table 1. Due to the limited experimental opportunity, only one run was conducted for one heat flux. In addition, identical ground experiments were also conducted for comparison.

\section{Results and discussion}

The transition of vapor bubble behavior and the mean surface temperature of the micro-pin-finned chip (denoted as Chip PF30$60)$ responding to the variation of gravity level for the heating $d c$ current of 0.26 and $0.34 \mathrm{~A}$ (corresponding to a heat flux of 7.2 and $12.53 \mathrm{~W} / \mathrm{cm}^{2}$ ) are shown in Figs. 4 and 5, respectively. The time positions of bubble behaviors presented in Fig. 4 are correspondingly marked on the curves of the mean temperature at different heating currents for chip PF30-60 shown in Fig. 5. The time for entering the microgravity condition is set to $0 \mathrm{~s}$. It is observed that before entering the microgravity condition, the vapor bubbles generate and departure continuously from the heating surface at a steady state due to the effect of buoyancy force (as shown in Fig. 4 at $-1 \mathrm{~s}$ ). At about $0.12 \mathrm{~s}$ after entering the microgravity condition, the vapor bubble begins to coalesce with each other to form a group of relatively larger bubbles attaching on the chip surface. Some small bubbles are still in the departure state when entering the microgravity condition, so they can be seen above the heater surface at this time. But the viscous forces and the absence of

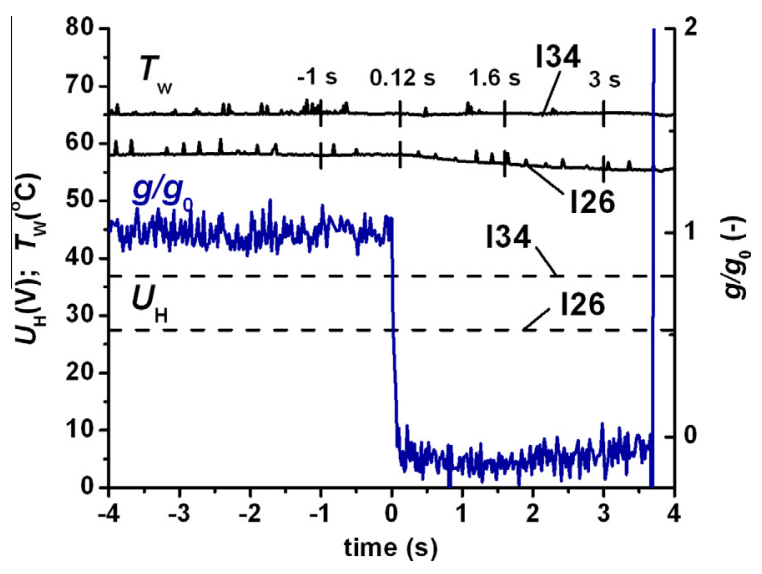

Fig. 5. Variations of the surface temperature, heating voltage, and gravity for $I=0.26 \mathrm{~A}$ and $I=0.34 \mathrm{~A}$.

buoyancy slow these small bubbles down in the bulk liquid. With increasing time, the bubbles further coalesce and form several much larger bubbles (as shown in Fig. 4 at $1.6 \mathrm{~s}$ ). When one coalesced bubble grows up to a certain size (as shown in Fig. 4 at $3 \mathrm{~s}$ ), it departs away from the heater surface according to the moving videos. Although the dramatically change of bubble behaviors, it is interesting to see from Fig. 5 that the mean heater surface temperature remains nearly constant (I34) or just a maximum decrease of about three centigrade (I26). This indicates that the reduction of gravity does not decrease the heat transfer but slightly enhance the performance in the low heat flux region (the isolated bubble regime) which may be due to the latent heat of vaporization at the base of large coalesced bubble attaching to the heater surface. Also, an enhancement of boiling heat transfer in microgravity was observed by Lee et al. [20].

Fig. 6 shows the bubble behaviors for the heating dc voltage of 55,63 and $66 \mathrm{~V}$ corresponding to a heat flux of 27.89, 36.07 and

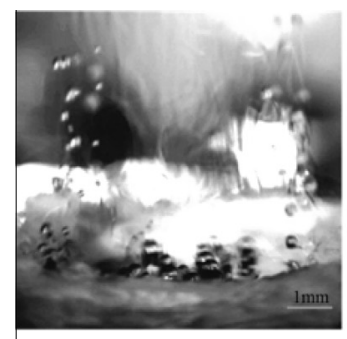

$-1 \mathrm{~s}$

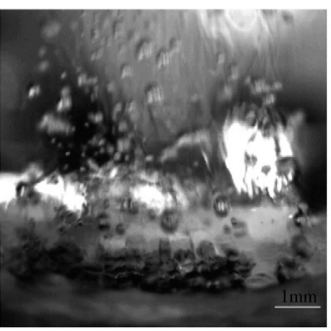

$-1 \mathrm{~s}$

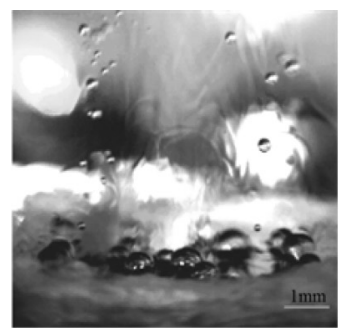

$0.12 \mathrm{~s}$

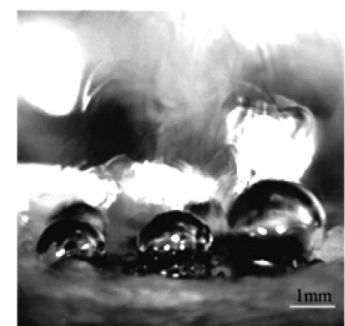

$1.6 \mathrm{~s}$

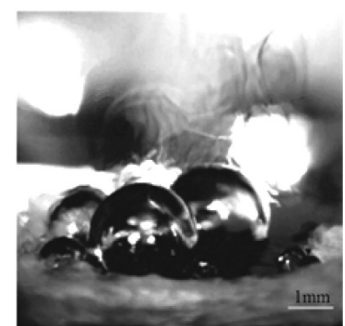

$3 \mathrm{~s}$

(a) $I=0.26 \mathrm{~A}$

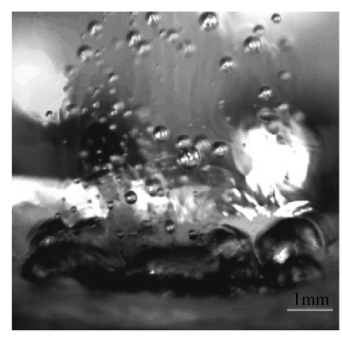

$0.12 \mathrm{~s}$

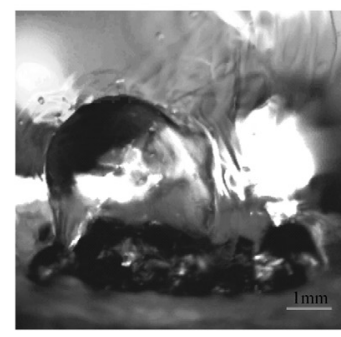

$1.6 \mathrm{~s}$

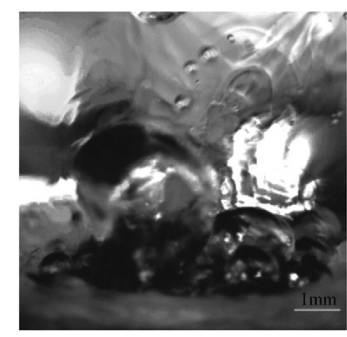

$3 s$

(b) $I=0.34 \mathrm{~A}$

Fig. 4. Bubble behavior under different gravity level and different heating current. 


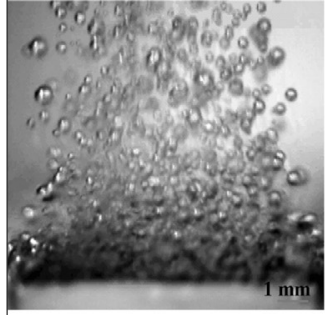

$-1 \mathrm{~s}$

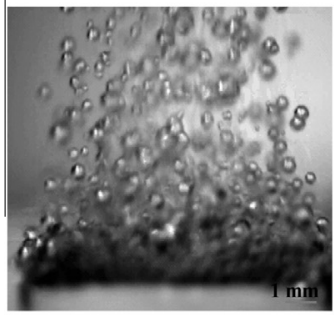

$-1 \mathrm{~s}$

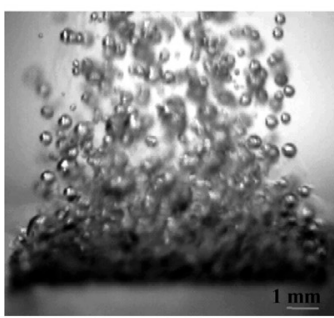

$-1 \mathrm{~s}$

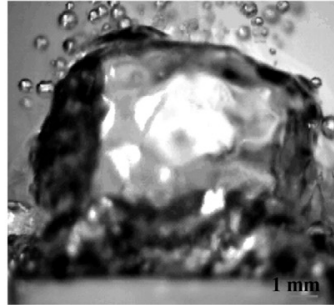

$0.12 \mathrm{~s}$

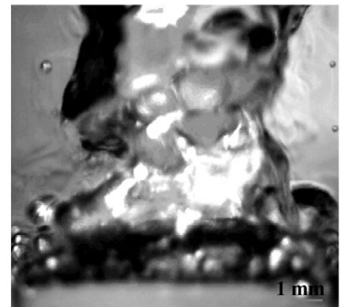

$1.6 \mathrm{~s}$

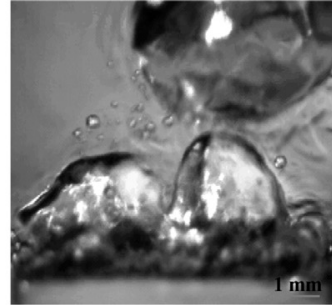

$3 \mathrm{~s}$

(a) $U=55 \mathrm{~V}$

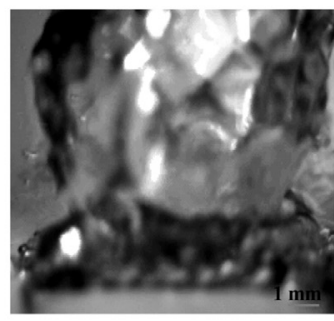

$0.12 \mathrm{~s}$

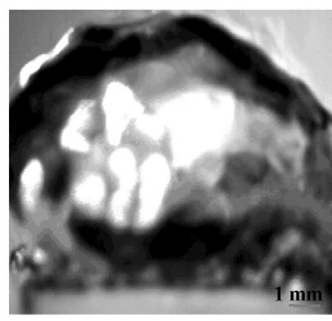

$1.6 \mathrm{~s}$

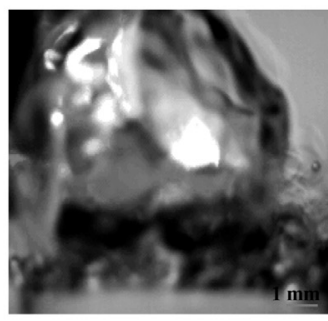

$3 \mathrm{~s}$

(b) $U=63 \mathrm{~V}$

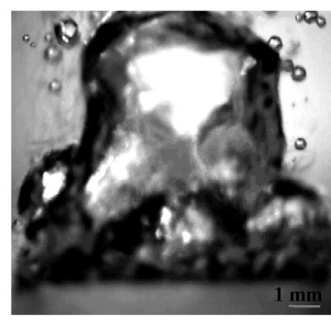

$0.12 \mathrm{~s}$

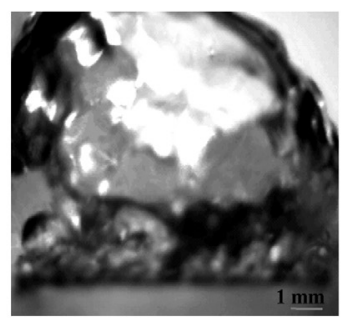

$1.6 \mathrm{~s}$

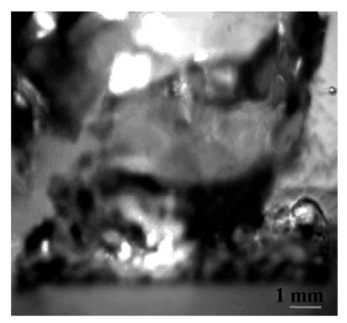

$3 \mathrm{~s}$

(c) $U=66 \mathrm{~V}$

Fig. 6. Bubble behavior under different gravity level and different heating voltage.

$39.54 \mathrm{~W} / \mathrm{cm}^{2}$, respectively. It should be mentioned that the heating method with constant heating voltage for chip PF30-60 is used in the second stages of experiment in order to achieve characteristics at high heat flux both in normal gravity and microgravity and avoid damage to the micro-pin-finned chip. In Fig. 6, it can be seen that before the beginning of the microgravity condition, the vapor bubbles keep generating and detaching as the case in Fig. 4 described above, just the bubble number increases with heat flux. After entering the microgravity condition, a vapor bubble slug develops and almost completely covers the heater surface at less than $0.1 \mathrm{~s}$ according to the moving videos. Then, with increasing time, vapor produces so rapidly that bubbles merge together in the vertical direction (as shown in Fig. 6 at 1.6 s), i.e., the large coalesced bubble attaching to the heater surface often coalesces with those that have been pulled away from the surface by the former bubbles, and finally columns of vapor slug rise up into the subcooled bulk liquid. Thereafter, the sustainable new generated bubbles on the heater surface repeat the above growth, coalescence and departure process (Fig. 6 at $3 \mathrm{~s}$ ). Since large bubbles are fed by liquid evaporation on the base and by coalescence with the smaller bubbles nearby, the large bubble detaches rapidly from the heater surface due to the momentum effects induced by intensive coalescence process during microgravity period. This departure mechanism was also confirmed by Straub [14] and was addressed as detachment bubble ripens. It also indicates that the bubble detachment is insensitive to the gravity reduction for the micro-pin-finned surface. However, normally under terrestrial conditions the bubbles cannot ripen because buoyancy force lifts them off previously.

The positions of Fig. 6(a)-(c) are marked on the curves of the mean heater surface temperature shown in Fig. 7 as well as heating current. It can be seen that the mean temperature of the case of U55 remains almost constant during the microgravity period.

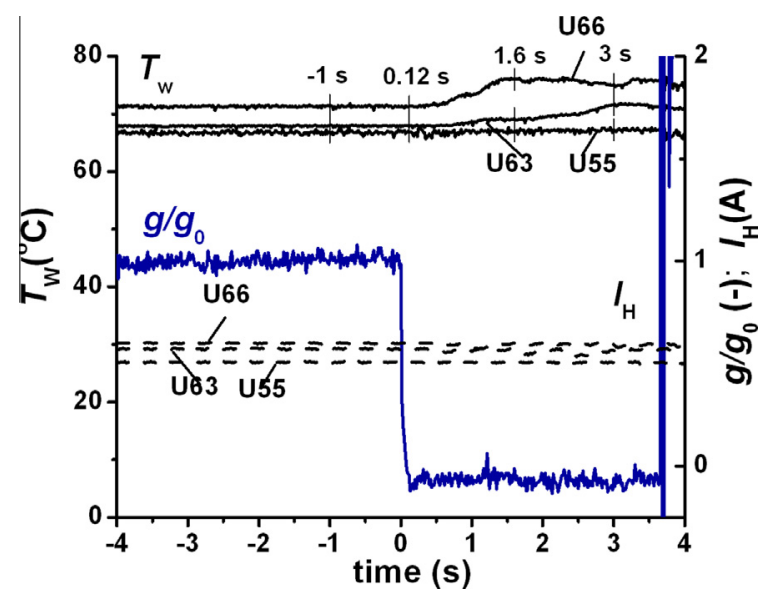

Fig. 7. Variations of the surface temperature, heating current and gravity for $U=55 \mathrm{~V}, U=63 \mathrm{~V}$ and $U=66 \mathrm{~V}$. 
Although the micro-pin-finned surfaces are covered by the large vapor slug, the capillary force generated by the bubbles drives plenty of fresh liquid into contact with the superheated wall for vaporization through the regular interconnected structures, as well as improves the micro-convection heat transfer by the motion of liquid around the micro-pin-fins. This phenomenon was also observed by Oka et al. [21]. They presented that the heater surface was almost completely blanketed with large vapor slugs from the side view, but from the rear view, there was a thin liquid layer like a "network" of wriggling "canals" of liquid which supplied to the heater surface for vaporization. Nevertheless, with further increase in the heat flux, the mean wall temperature of cases of U63 and U66 increase slightly with time elapse in microgravity condition in Fig. 7 until it reaches its maximum peak and simultaneously adjusts itself to a quasi-steady state. According to the moving videos of test, it can be inferred that the change of the trend of the mean temperature curve is mainly dominated by the competition between enhancement heat transfer through the small bubbles generated at the base of the large coalesced bubble and deterioration heat transfer by the extension of dry patches under the large coalesced bubble. Also, Lee et al. [20] confirmed that a direct relationship exists between the variation of the mean heater surface temperature and the dry ration. As a result, the slight increase in the mean heater surface temperature at high heat flux regions can be attributed directly to the increase of partial dryout of the heater surface. It may be that the capillary force increases with the heat flux and reaches its maximum value which could not overcome the hydraulic resistances of the wet liquid to access everywhere in the micro-pin-fins interconnected channel. Thus, the liquid near some micro-pin-fins is used up due to shortage of fresh liquid supply, which leads to the increase of wall temperature with partial dryout.

Fig. 8 presents the boiling curves of chip PF30-60 under different gravity levels, and the results of chip S previously published in Ref. [19] are also shown for comparison. Also, the smooth surface and micro-pin-finned surface in microgravity are conducted in the same experimental facility and procedure. By the way, the liquid subcooling for smooth surface experiment is about $41 \mathrm{~K}$ (corresponding to $15^{\circ} \mathrm{C}$ of bulk liquid temperature) which is also caused by ambient temperature. For chip PF30-60, eight run tests under microgravity conditions at eight different heat fluxes respectively are carried out with two heating methods. One is the constant heating current method in the low heat fluxes region of $7.2-27.2 \mathrm{~W} / \mathrm{cm}^{2}$ for the first four cases such as I26, I34, I42, I50 listed in Table 1, another is the constant heating voltage method

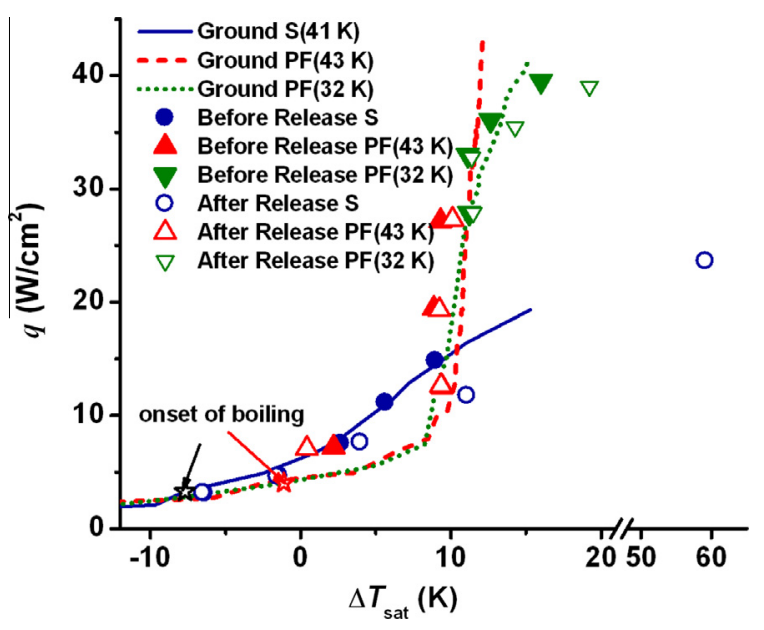

Fig. 8. Boiling curves for chips S and PF30-60 in different gravity levels. for the last four cases in Table 1 as heat fluxes exceed $27.2 \mathrm{~W} /$ $\mathrm{cm}^{2}$. We could not control the same temperature condition of working fluid at different experiments, because there is no preheater and no temperature control for working fluid system. The liquid subcooling of FC-72 corresponding to the above mentioned two heating methods are 43 and $32 \mathrm{~K}$, respectively, which is determined by the ambient temperature. In our previous experimental study [22], we found that the larger the liquid subcooling, the better the boiling heat transfer performance is obtained for both smooth surface and micro-pin-finned surface. In Fig. 8, the liquid subcooling of micro-pin-finned surface is lower than that of smooth surface in fully developed nucleate boiling region, but better heat transfer performance was observed than that of smooth surface. Moreover, the present study focuses on the boiling heat transfer performance of the fully developed nucleate pool boiling. Therefore, it can be inferred that the micro-pin-finned surface will show much better heat transfer performance at the same liquid subcooling as the smooth surface. So, comparison between micro-pin-finned surface and smooth surface at different subcooling degrees can be made in present experiments to show reasonably the heat transfer merits of micro-pin-finned chip. Additionally, ground test runs with the same hardware and software as microgravity drop tower experiments were conducted previously to make sure reliability and rationality of the experimental system and determined effective heat flux range of nucleate pool boiling heat transfer for the drop tower experiments.

It can be seen that the chips PF30-60 and $S$ follow almost the same $q$ vs. $\Delta T_{\text {sat }}$ relation in the non-boiling region under ground experiment condition, which demonstrates the micro-pin-finned structure has a negligible effect on the natural convection heat transfer. With the increase of heat flux, the boiling incipience occurs and the heat transfer performance of smooth surfaces differs from micro-pin-finned surfaces. It shows that boiling occurs more earlier on chip S than on chip PF30-60. The onset of boiling for chip $\mathrm{S}$ corresponds to a lower wall superheat value of $-7.7 \mathrm{~K}$, while chip PF30-60 has higher wall superheat about $-1.1 \mathrm{~K}$ (the boiling starts at a negative value of $\Delta T_{\text {sat }}$ due to the effect of dissolved air in the liquid of FC-72, which decreases the true saturation temperature of liquid, resulting in a negative value of wall superheat at the onset of boiling). Thus, the heat transfer on the smooth surface is better than that on the micro-pin-finned surface in the heat flux regimes of $2.7-4.0 \mathrm{~W} / \mathrm{cm}^{2}$. However, in the heat flux regimes of $4.0-$ $15.0 \mathrm{~W} / \mathrm{cm}^{2}$, the smooth surface still has a better boiling heat transfer performance than micro-pin-finned surface. This can be explained as follows. The cool liquid around the micro-structures was convected by the suction effects due to bubble generation from the micro-pin-finned surface. The motion of the liquid increases the area of heat transfer and improves the micro-convection heat transfer. The enhanced single-phase convective heat transfer can be enough to dissipate the increased heat fluxes. For the smooth surface, the single-phase convection heat transfer cannot dissipate the increased heat fluxes, but only enhances boiling heat transfer by increasing more nucleation sites and the activated bubble can dissipate the increased heat fluxes. So, the heat transfer for the smooth surface is dominated by nucleate boiling heat transfer while the micro-pin-finned surface by single-phase convection heat transfer. This induces the better performance of the heat transfer of smooth surface than that of the micro-fin-finned surface in the range of heat fluxes $4.0-15 \mathrm{~W} / \mathrm{cm}^{2}$. As the heat fluxes exceed $15 \mathrm{~W} / \mathrm{cm}^{2}$, the micro-convection heat transfer pumped by a few bubble in the gaps between the adjacent pin fins cannot dissipate the increased heat fluxes. More nucleation sites are activated and fully developed boiling heat transfer dominates the heat transfer process. Furthermore, the boiling heat transfer performance on the micro-pin-finned surface prevails upon that on smooth surface because of the enhancement effects of micro-structures. So the 
micro-pin-finned chip showed more excellent performance than those of smooth chip. Moreover, the boiling curve of chip PF3060 is very steep and the wall superheat shows a very small change with further increasing to the high heat flux region. This phenomenon was also observed by Honda et al. [23] and Wei et al. [10].

The solid symbol denoting the normal gravity data before the release drop tower has been shown in Fig. 8. It is seen that the normal gravity data points for chip S show good agreement with ground experiment data, while the normal gravity data for chip PF30-60 deviates from the ground test. This is probably due to the effect of residual micro-bubbles within micro-pin-fins after the preceding ground runs. These micro-bubbles would make the micro-pin-fins easier to become effective nucleation sites, and boiling heat transfer performance of the first seven runs with a lower wall superheat and of the last runs with a higher wall superheat.

In the low heat flux region shown in Fig. 8, the heat transfer of chip PF30-60 under microgravity condition is slightly better than that of normal gravity condition. This is because the evaporation is enhanced through the increase of interface area between liquid microlayer and vapor bubble in the isolated bubble regime for microgravity case. With increase in heat flux, the heat transfer for microgravity and normal gravity cases are almost exactly consistent. Thus, the heat transfer in coalesced bubble regime is independent of gravity, or at least, dependent very weakly on gravity in the intermediate heat fluxes region shown in Fig. 8. And the boiling curves for chip PF30-60 show a substantial increase in $q$ with minor increase of $\Delta T_{\text {sat }}$ under both normal gravity and microgravity conditions. With further increasing the heat flux to about $36 \mathrm{~W} /$ $\mathrm{cm}^{2}$, the boiling curves for chip PF30-60 under microgravity conditions show a bend and the slopes decrease severely at higher heat flux value. Thus, the mean temperature of the heater surface is slightly increased compared with that of normal gravity. This is probably because partial vapor below the large coalesced bubble generated in the gaps between the adjacent pin fins prevents fresh bulk liquid from accessing the heater surface for evaporation heat transfer, which makes the removal of heat transfer difficult and leads to a general increase in heater temperature.

Much evident deterioration of heat transfer for chip S in high heat flux region can be observed under microgravity in Fig. 8. In addition, it is found that the mean heater surface superheat of chip $S$ under microgravity condition is substantially larger than that in normal gravity. However, it can be clearly seen that the micro-pinfinned chip PF30-60 shows considerable heat transfer enhancement compared to chip $S$ under microgravity condition. The presented upper limit heat flux for chip PF30-60 is much higher than that of chip $S$ while the corresponding mean heater surface superheat is much lower than that of chip $S$ under microgravity conditions.

\section{Conclusions}

Experiments were conducted to study the effect of micro-pinfinned on boiling heat transfer enhancement using a square silicon chip $\left(10 \times 10 \times 0.5 \mathrm{~mm}^{3}\right)$ in subcooled pool boiling of FC-72 under short-term microgravity and earth gravity conditions respectively, and the following conclusions can be obtained:

(1) The bubble dynamic behaviors of nucleate pool boiling on the micro-pin-finned chip under microgravity is characterized by a larger number of nucleation sites and a group of relatively larger bubbles formed by vigorous bubble coalescence. These larger bubbles further coalesce into a large necking vapor slug and grow up continuously until the slug departs away from the heater surface. Therefore, periodical bubble growth, coalescence and detachment result in the mean temperature of micro-pin-finned surface keeping almost steady or quasi-steady state under both gravity and microgravity conditions.

(2) At low heat fluxes, the boiling heat transfer of micro-pinfinned under microgravity is slightly better than that of normal gravity condition. With increase in heat flux, the heat transfer for microgravity and normal gravity cases are almost exactly consistent. But increasing heat fluxes to about $36 \mathrm{~W} / \mathrm{cm}^{2}$, the slope of boiling curve in microgravity is slightly decreased, i.e., heat transfer performance deteriorates gently. Furthermore, the micro-pin-finned chip PF3060 shows considerable heat transfer enhancement with higher upper limit heat flux and lower mean heater surface superheat compared to chip S under microgravity condition.

(3) The performance of high efficient heat transfer on micropin-finned surface is independent of the gravity, which stems from the sufficient supply of fresh liquid to heater surface due to the capillary driving force caused by a bubble hovering on the top of micro-pin-fins. Since the capillary force is not related to the gravity level, the micro-pin-finned surface appears to be one promising enhanced surface for efficient electronic components cooling schemes not only in normal gravity but also under microgravity conditions, which is very helpful to reduce the cooling system weight in space and in planetary neighbors.

\section{Acknowledgments}

We gratefully acknowledge the financial support from the National Natural Science Foundation of China under the Grants of 51225601 and 10972225, the Fundamental Research Funds for the Central Universities, and the support from the Key Laboratory of Microgravity/CAS for experiments utilizing the drop tower Beijing. The author would like to thank the Drop tower staff for their help in the present experiments.

\section{References}

[1] Y. Abe, T. Oka, Y.H. Mori, A. Nagashima, Pool boiling of a non-azeotropic binary mixture under microgravity, Int. J. Heat Mass Transfer 37 (1994) 2405-2413.

[2] S. Oktay, Departure from natural convection (DNC) in low-temperature boiling heat transfer encounted in cooling micro-electronic LSI devices, in: Proceeding of 7th International Heat Transfer Conference, Munich, 1982, pp. 113-118.

[3] U.P. Hwang, K.P. Moran, Boiling heat transfer of silicon integrated circuits chip mounted on a substrate, ASME Heat Transfer Electron. Equip. 20 (1981) 53-59.

[4] H. Kubo, H. Takamatsu, H. Honda, Effects of size and number density of microreentrant cavities on boiling heat transfer from a silicon chip immersed in degassed and gas dissolved FC-72, J. Enhanced Heat Transfer 6 (1999) 151160.

[5] J.P. O'Connor, S.M. You, D.C. Price, A dielectric surface coating technique to enhance boiling heat transfer from high power microelectronics, IEEE Trans. Compon. Packag. Manuf. Technol. 18 (1995) 656-663.

[6] J.Y. Chang, S.M. You, Heat orientation effects on pool boiling of micro-porousenhanced surfaces in saturated FC-72, ASME J. Heat Transfer 118 (1996) 937943.

[7] J.Y. Chang, S.M. You, Enhanced boiling heat transfer from micro-porous surfaces: effects of a coating composition and method, Int. J. Heat Mass Transfer 40 (1997) 4449-4460.

[8] H. Honda, H. Takamastu, J.J. Wei, Enhanced boiling of FC-72 on silicon chips with micro-pin-fins and submicron-scale roughness, ASME J. Heat Transfer 124 (2002) 383-390.

[9] J.J. Wei, H. Honda, Effects of fin geometry on boiling heat transfer from silicon chips with micro-pin-fins immersed in FC-72, Int. J. Heat Mass Transfer 46 (2003) 4059-4070.

[10] J.J. Wei, L.J. Guo, H. Honda, Experimental study of boiling phenomena and heat transfer performances of FC-72 over micro-pin-finned silicon chips, Heat Mass Transfer 41 (2005) 744-755

[11] A.X. Ma, J.J. Wei, M.Z. Yuan, J.B. Fang, Enhanced flow boiling heat transfer of FC-72 on micro-pin-finned surfaces, Int. J. Heat Mass Transfer 52 (2009) 29252931.

[12] M.Z. Yuan, J.J. Wei, Y.F. Xue, J.B. Fang, Subcooled flow boiling heat transfer of FC-72 from silicon chips fabricated with micro-pin-fins, Int. J. Therm. Sci. 48 (2009) 1416-1422. 
[13] P. Di Marco, Influence of force fields and flow patterns on boiling heat transfer performance: a review, J. Heat Transfer 134 (2012) 030801-030815.

[14] J. Straub, Boiling heat transfer and bubble dynamics in microgravity, Adv. Heat Transfer 35 (2001) 57-172.

[15] P. Di Marco, Review of reduced gravity boiling heat transfer, European research, J. Jpn. Microgravity Appl. 20 (2003) 252-263.

[16] J. Kim, Review of reduced gravity boiling heat transfer, US research, J. Jpn Microgravity Appl. 20 (2003) 264-271.

[17] H. Ohta, Review of reduced gravity boiling heat transfer, Japanese research, J. Jpn. Microgravity Appl. 20 (2003) 272-285.

[18] J.F. Zhao, Two-phase flow and pool boiling heat transfer in microgravity, Int. J. Multiphase Flow 36 (2010) 35-143.

[19] Y.F. Xue, J.F. Zhao, J.J. Wei, J. Li, D. Guo, S.X. Wan, Experimental study of nucleate pool boiling of FC-72 on smooth surface under microgravity, Microgravity Sci. Technol. 23 (2011) 75-85.
[20] H.S. Lee, H. Merte, F. Chiaramonte, The pool boiling curve in microgravity, J. Thermophys. Heat Transfer 11 (1997) 216-222.

[21] T. Oka, Y. Abe, Y.H. Mori, A. Nagashima, Pool boiling of n-pentane, CFC-113, and water under reduced gravity: parabolic flight experiments with a transparent heater, ASME J. Heat Transfer 117 (1995) 408-417.

[22] Y.F. Xue, M.Z. Yuan, A.X. Ma, J.J. Wei, Enhanced boiling heat transfer by using micro-pin-finned surface in three different test systems, Heat Transfer Eng. 32 2011) $1062-1068$

[23] H. Honda, H. Takamatsu, J.J. Wei, Enhanced boiling heat transfer from silicon chips with micro-pin fins immersed in FC-72, J. Enhanced Heat Transfer 10 (2003) 211-223. 